\title{
Diagnosing Urinary Tract Infections
}

Ann Fam Med 2013;iii. doi:10.1370/afm.1566.

$\mathrm{T}$ The Annals of Family Medicine encourages readers to develop a learning community of those seeking to improve health care and health through enhanced primary care. You can participate by conducting a RADICAL journal club and sharing the results of your discussions in the Annals online discussion for the featured articles. RADICAL is an acronym for Read, Ask, Discuss, Inquire, Collaborate, Act, and Learn. The word radical also indicates the need to engage diverse participants in thinking critically about important issues affecting primary care and then acting on those discussions. ${ }^{1}$

\section{HOW IT WORKS}

In each issue, the Annals selects an article or articles and provides discussion tips and questions. We encourage you to take a RADICAL approach to these materials and to post a summary of your conversation in our online discussion. (Open the article online and click on "TRACK Comments: Submit a response.") You can find discussion questions and more information online at: http://www.AnnFamMed.org/AJC/.

\section{CURRENT SELECTION}

\section{Article for Discussion}

Knottnerus BJ, Geerlings SE, Moll van Charante EP, ter Riet G. Toward a simple diagnostic index for acute uncomplicated urinary tract infections. Ann Fam Med. 2013;11(5):442-451.

\section{Discussion Tips}

Urinary tract infections are common, and clinicians' diagnostic approaches are based on long tradition, local practice, and personal experience. This interesting clinical study provides empirical information on the conjoint diagnostic value of combinations of medical history and simple laboratory testing for acute uncomplicated urinary tract infections in women with painful and/or frequent urination.

\section{Discussion Questions}

- What question is asked by this study, and why does it matter?

- How does this study advance beyond previous research and clinical practice on this topic?

- How strong is the study design for answering the question?

- To what degree can the findings be accounted for by:

1. How patients were selected, excluded, or lost to follow-up?

2. How the main variables were measured?

3. Confounding (false attribution of causality because 2 variables discovered to be associated actually are associated with a 3 rd factor)?

4. Chance?

5. How the findings were interpreted?

- What do you think of the outcome variable?

- How comparable is the study sample to similar patients in your practice? What is your judgment about the transportability of the findings?

- What are the main study findings?

- Which approach indicated by the different models do you think you are likely to use, and how might your approach vary based on patient characteristics?

- Do you think the findings have implications for selftreatment by selected patients?

-What are the next steps in interpreting or applying the findings?

- What researchable questions remain?

\section{References}

1. Stange KC, Miller WL, McLellan LA, et al. Annals Journal Club: It's time to get RADICAL. Ann Fam Med. 2006;4(3):196-197. http:// annfammed.org/cgi/content/full/4/3/196. 